\title{
Are women aware of the importance of mammography in breast cancer diagnosis and screening?
}

\author{
Serap ULUSOY', İbrahim KILINC' ${ }^{1}$, Burcu AKKURT ${ }^{3}$, Ömer PARLAK ${ }^{2}$ \\ ${ }^{1}$ Department of General Surgery, Ankara City Hospital, Ankara, Turkey \\ ${ }^{2}$ Department of General Surgery, Faculty of Medicine, Yıldırım Beyazıt University, Ankara, Turkey \\ ${ }^{3}$ Familiy Medicine, Elmadağ State Hospital, Ankara, Turkey \\ Correspondence \\ Serap ULUSOY \\ Ankara Şehir Hastanesi, Genel Cerrahi Bölümü, Ankara, Türkiye \\ e-mail: serapulusoy13@gmail.com
}

\section{ABSTRACT}

This study aimed to reveal the experience and knowledge of women concerning mammography and raise awareness of mammography and breast cancer.

A mammography awareness survey was administered to 500 women aged between 40 and 69 years. A total of 434 women knew mammography, while the remaining 66 women were not aware of mammography. Of all respondents, 341 had previously undergone mammography, mostly with the recommendation of their doctors, while 159 participants had not undergone this procedure, mostly stating that they did not consider it necessary. In the group with a history of mammography, difficulties during scanning were reported by 196 women, of whom 187 reported having pain. Of all respondents, 407 stated that they would have mammography in the future whereas 93 denied it.

Education level and willingness to undergo mammography in the future were significantly higher in those with a history of mammography compared with the non-mammography group $(P<0.05$ for both). The education status was also significantly higher in women who planned to undergo mammography compared with the women who denied it in the future $(P<0.05)$. The rate of fear of radiation exposure during scanning was significantly higher among the women without a history of mammography, who also did not plan to undergo this procedure in the future, compared with those who were willing to undergo this procedure $(P<0.05)$. However, other reasons for not undergoing mammography did not differ significantly between the two groups $(P$ $>0.05)$. Increasing the awareness in society on breast cancer and mammography may facilitate the detection and treatment of breast cancer. Mammography is the most effective imaging method in detecting breast cancer. Understanding the perspective of women aged 40-69 years concerning this procedure and conducting appropriate studies in this direction may increase the rate of mammography in society and contribute to the early detection of breast cancer.

Key words: Breast cancer, breast cancer diagnosis, mammography anxiety, mammography screening

\section{INTRODUCTION}

Breast cancer is the most common cancer causing death among women worldwide and in Turkey. According to the 2018 data of the World Health Organization, the global number of patients with newly diagnosed breast cancer was 2,000,088, and the number of those who died of breast cancer was 626,679 (1). Cancer-related mortality and morbidity decrease when breast cancer can be detected, especially in the early stages. One of the most effective ways to diagnose cancer early is community screen- ing. Mammography is the most commonly used and most experienced screening tool in the world. As an effective, easily accessible, reproducible, and inexpensive examination method, mammography is considered to be the most important test in breast cancer screening; however, the desired level of mammography screening has not yet been reached, especially in developing countries. Reasons accounting for this situation may include social, cultural, economic, demographic, and geographical factors. 
This study was performed to reveal the experience and knowledge of women concerning mammography and investigate their reasons for not undergoing mammography so as to determine the ways to increase the rate of mammography in the society and raise awareness of the importance of this procedure and breast cancer.

\section{MATERIAL AND METHODS}

This study was approved by the clinical research ethics committee of Yıldırım Beyazıt University Faculty of Medicine (decision number 205 dated March 10, 2018). Verbal consent was obtained, and the mammography awareness questionnaire was administered to 500 women aged $40-69$ years who visited the general surgery outpatient clinic for varied reasons. The questionnaire consisted of 10 items prepared in line with the literature. The first three items concerned the sociodemographic characteristics of the participants, and the remaining items referred to the experience and knowledge of the participants concerning mammography. The data obtained were grouped. In the descriptive statistics of the data, mean, standard deviation, median minimum, maximum, frequency, and ratio values were used. The distribution of the variables was measured using the Kolmogorov-Smirnov test. One-way analysis of variance (Tukey's test), independent-samples $t$ test, Kruskal-Wallis test, and Mann-Whitney $U$ test were used to analyze quantitative independent data. A chi-square test was conducted for analyzing qualitative independent data, and Fischer's test was employed when the chi-square test conditions were not met. SPSS v. 22.0 was used for the statistical analysis.

\section{RESULTS}

The mean age of the participants was 53 years. Of all participants, $382(76.4 \%)$ were housewives, 28 (5.6\%) were retired, and 90 (18\%) were actively working. In terms of education status, 48 (9.6\%) women were illiterate, while 256 (51.2\%) graduated from primary school, 41 (8.2\%) from middle school, 76 (15.2\%) from high school, and 79 (15.8\%) from the university.

In response to the question, “Do you know what mammography is?" included in the second part of the mammography questionnaire, 434 (86.8\%) women answered "yes" and 66 (13.2\%) "no." Of the 500 women participating in the study, 341 (68.2\%) had previously undergone mammography (mammography group) while 159 (31.8\%) had never undergone this procedure (non-mammography group). When the women in the mammography group were asked about the factors effective in their decision to undergo this procedure, $243(71.3 \%)$ stated that it was their doctors' recommendation, 7 (2.1\%) had read about it on the media, $20(5.9 \%)$ had received a recommendation from the people they knew (neighbors, friends, etc.), 26 (7.6\%) had a family history of cancer, 31 (9.1\%) wanted to have an early diagnosis in case they had cancer, and $14(4.1 \%)$ had a mammogram due to a breast mass. In the non-mammography group, the reasons for not undergoing this procedure were reported as not being necessary $(n=85)$, not having any knowledge of the procedure $(n=44)$, fear of pain $(n=13)$, radiation exposure during scanning $(n=7)$, anxiety related to cancer diagnosis $(n=5)$, and financial hardship ( $n=$ 5). Of the 341 women in the mammography group, 145 did not experience any difficulties during the procedure while 196 reported various difficulties related to pain ( $n=187$ ), being half-naked during scanning $(n=6)$, fear of having a cancer diagnosis $(n=2)$, and the technician's lack of guidance $(n=1)$. The question, "Are you planning to undergo mammography in the future" was answered "yes" by 407 of the 500 women who participated in the survey and "no" by the remaining 93 respondents.

The rate of retired women was significantly higher in the mammography group, while the rate of housewives was significantly higher in the non-mammography group ( $P<0.05$ for both). As expected, the education status of the women in the mammography group was significantly higher than that in the nonmammography group $(P<0.05)$. The intention of undergoing mammography in the future was significantly higher in the mammography group compared with the non-mammography group $(P<0.05)$ (Table 2$)$.

The age of the patients who planned to have mammography in the future was significantly lower than that of patients who denied it $(P<0.05)$. The rate of retired or employed women was significantly higher in those considering mammography, while the rate of housewives was significantly higher in those who denied it $(P<0.05)$. The educational level and the rate 
Table 1 General data

\begin{tabular}{|c|c|c|c|c|c|c|c|c|}
\hline & & \multicolumn{3}{|c|}{ Min-max } & \multirow{2}{*}{$\begin{array}{c}\text { Median } \\
53.0\end{array}$} & \multicolumn{3}{|c|}{ Mean \pm SD/n, \% } \\
\hline \multicolumn{2}{|l|}{ Age (year) } & 40.0 & - & 69.0 & & 53.3 & \pm & 7.2 \\
\hline \multirow{3}{*}{ Age groups } & $40-49$ & & & & & 166 & & $33.2 \%$ \\
\hline & $50-59$ & & & & & 229 & & $45.8 \%$ \\
\hline & $\geq 60$ & & & & & 105 & & $21.0 \%$ \\
\hline \multirow{3}{*}{ Employment status } & Housewife & & & & & 382 & & $76.4 \%$ \\
\hline & Retired & & & & & 28 & & $5.6 \%$ \\
\hline & Employed & & & & & 90 & & $18.0 \%$ \\
\hline \multirow{5}{*}{ Education status } & Illiterate & & & & & 48 & & $9.6 \%$ \\
\hline & Primary school & & & & & 256 & & $51.2 \%$ \\
\hline & Middle school & & & & & 41 & & $8.2 \%$ \\
\hline & High school & & & & & 76 & & $15.2 \%$ \\
\hline & University & & & & & 79 & & $15.8 \%$ \\
\hline \multirow[t]{2}{*}{ Knowledge of mammography } & No & & & & & 66 & & $13.2 \%$ \\
\hline & Yes & & & & & 434 & & $86.8 \%$ \\
\hline \multirow{2}{*}{ History of mammography } & Yes & & & & & 341 & & $68.2 \%$ \\
\hline & No & & & & & 159 & & $31.8 \%$ \\
\hline If yes, why? & & & & & & 341 & & $68.2 \%$ \\
\hline Doctor's recommendation & & & & & & 243 & & $71.3 \%$ \\
\hline \multicolumn{2}{|l|}{ Read about it on the media } & & & & & 7 & & $2.1 \%$ \\
\hline \multicolumn{2}{|l|}{ Recommended by a neighbor, friend, etc. } & & & & & 20 & & $5.9 \%$ \\
\hline Family history of cancer & & & & & & 26 & & $7.6 \%$ \\
\hline \multicolumn{2}{|l|}{ For early cancer detection if present } & & & & & 31 & & $9.1 \%$ \\
\hline Breast mass & & & & & & 14 & & $4.1 \%$ \\
\hline \multicolumn{2}{|l|}{ If no, why? } & & & & & 159 & & $31.8 \%$ \\
\hline \multicolumn{2}{|l|}{ Fear of radiation exposure during the procedure } & & & & & 7 & & $4.4 \%$ \\
\hline \multicolumn{2}{|l|}{ Fear of a cancer diagnosis } & & & & & 5 & & $3.1 \%$ \\
\hline \multicolumn{2}{|l|}{ Fear of pain during the procedure } & & & & & 13 & & $8.2 \%$ \\
\hline Considered unnecessary & & & & & & 85 & & $53.5 \%$ \\
\hline \multicolumn{2}{|l|}{ Financial hardship } & & & & & 5 & & $3.1 \%$ \\
\hline \multicolumn{2}{|l|}{ No knowledge of mammography } & & & & & 44 & & $27.7 \%$ \\
\hline \multirow{2}{*}{ Difficulties during mammography } & No & & & & & 145 & & $42.5 \%$ \\
\hline & Yes & & & & & 196 & & $57.5 \%$ \\
\hline Pain & & & & & & 187 & & $54.8 \%$ \\
\hline Being half-naked & & & & & & 6 & & $1.8 \%$ \\
\hline \multicolumn{2}{|l|}{ Fear of a cancer diagnosis } & & & & & 2 & & $0.6 \%$ \\
\hline \multicolumn{2}{|l|}{ Technician's lack of guidance } & & & & & 1 & & $0.3 \%$ \\
\hline \multirow{2}{*}{$\begin{array}{l}\text { Planning to undergo mammography in the } \\
\text { future }\end{array}$} & No & & & & & 93 & & $18.6 \%$ \\
\hline & Yes & & & & & 407 & & $81.4 \%$ \\
\hline
\end{tabular}


Table 2 Mammography experience

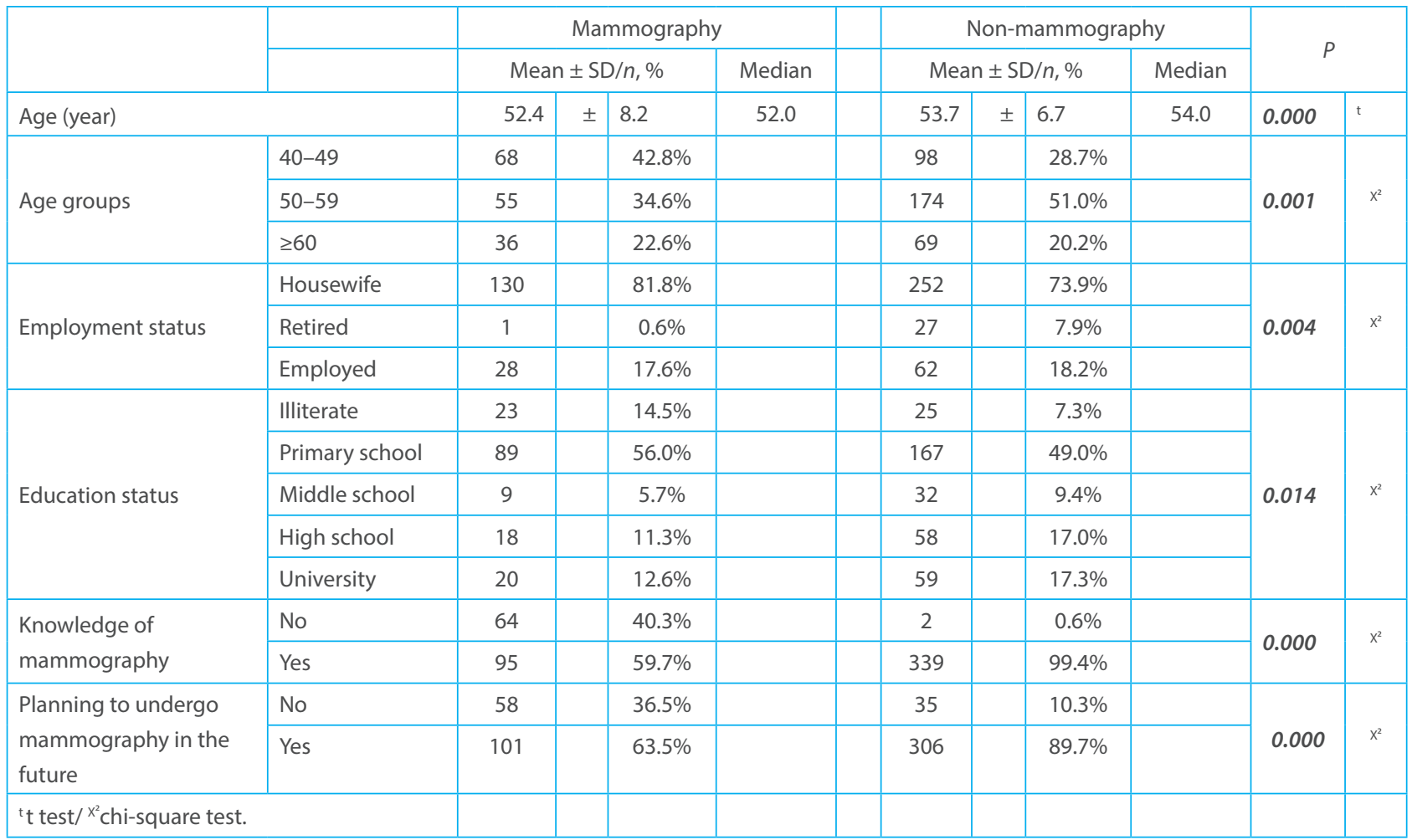

of knowledge of mammography were significantly higher in the group that planned to undergo mammography than in the group that denied it $(P<0.05$ for both) (Table 3).

In the non-mammography group, the women who did not intend to undergo this procedure had a significantly higher rate of fear of radiation exposure compared with those who planned to undergo this procedure in the future $(P<0.05)$; however, other reasons for not considering this procedure in the future did not significantly differ between these two groups $(P>0.05)$ (Table 3).

In the mammography group, no significant difference was found between the women with and without an intention of undergoing mammography again (Table 3).

The age of the patients in the group that experienced difficulties during mammography was significantly higher than that in the group reporting no difficulty $(P<0.05)$. However, no significant difference was observed between these two groups in terms of employment or education status $(P>0.05$ for both) (Table 4).

\section{DISCUSSION}

Breast cancer is most common among women worldwide and in Turkey; it is also the most common cause of cancer-related death.

The stage of cancer at the time of diagnosis is of great importance in determining the treatment and the subsequent course of the disease. Breast ultrasonography (USG), mammography, and magnetic resonance imaging (MRI) are increasingly used to diagnose breast cancer in recent years. Ultrasonography is the first imaging method used especially in patients aged less than 40 years with dense breast tissue. USG has been used to support screening mammography for many years. In women with dense breast tissue with low MMG sensitivity, the addition of USG has increased not only the rate of cancer detection but also also the recall and unnecessary biopsy rates. 
Table 3 Intentions regarding future procedure

\begin{tabular}{|c|c|c|c|c|c|c|c|c|c|c|c|}
\hline \multirow{3}{*}{\begin{tabular}{|l|} 
\\
Age (year) \\
\end{tabular}} & & \multicolumn{4}{|c|}{ Intention to undergo mammography } & \multicolumn{4}{|c|}{$\begin{array}{l}\text { No intention to undergo } \\
\text { mammography }\end{array}$} & \multirow[b]{3}{*}{0.016} & \multirow[b]{3}{*}{ t } \\
\hline & & \multicolumn{3}{|c|}{ Mean $\pm \mathrm{SD} / n, \%$} & \multirow{2}{*}{$\begin{array}{c}\text { Median } \\
55.0\end{array}$} & \multicolumn{3}{|c|}{ Mean $\pm \mathrm{SD} / n, \%$} & \multirow{2}{*}{$\begin{array}{c}\text { Median } \\
52.0\end{array}$} & & \\
\hline & & 55.1 & \pm & 7.6 & & 52.8 & \pm & 7.1 & & & \\
\hline \multirow{3}{*}{ Age groups } & $40-49$ & 21 & & $22.6 \%$ & & 145 & & $35.6 \%$ & & \multirow{3}{*}{0.005} & \multirow{3}{*}{$x$} \\
\hline & $50-59$ & 42 & & $45.2 \%$ & & 187 & & $45.9 \%$ & & & \\
\hline & $\geq 60$ & 30 & & $32.3 \%$ & & 75 & & $18.4 \%$ & & & \\
\hline \multirow{3}{*}{ Employment status } & Housewife & 79 & & $84.9 \%$ & & 303 & & $74.4 \%$ & & \multirow{3}{*}{0.031} & \multirow{3}{*}{$x$} \\
\hline & Retired & 2 & & $2.2 \%$ & & 26 & & $6.4 \%$ & & & \\
\hline & Employed & 12 & & $12.9 \%$ & & 78 & & $19.2 \%$ & & & \\
\hline \multirow{5}{*}{ Education status } & Illiterate & 17 & & $18.3 \%$ & & 31 & & $7.6 \%$ & & \multirow{5}{*}{0.014} & \multirow{5}{*}{$x^{2}$} \\
\hline & Primary school & 49 & & $52.7 \%$ & & 207 & & $50.9 \%$ & & & \\
\hline & Middle school & 7 & & $7.5 \%$ & & 34 & & $8.4 \%$ & & & \\
\hline & High school & 9 & & $9.7 \%$ & & 67 & & $16.5 \%$ & & & \\
\hline & University & 11 & & $11.8 \%$ & & 68 & & $16.7 \%$ & & & \\
\hline \multirow{2}{*}{$\begin{array}{l}\text { Knowledge of } \\
\text { mammography }\end{array}$} & No & 22 & & $23.7 \%$ & & 44 & & $10.8 \%$ & & \multirow{2}{*}{0.001} & \multirow{2}{*}{$x^{2}$} \\
\hline & Yes & 71 & & $76.3 \%$ & & 363 & & $89.2 \%$ & & & \\
\hline \multicolumn{12}{|c|}{ If had previous mammography, why? } \\
\hline Doctor's recommen & tion & 22 & & $62.9 \%$ & & 221 & & $72.2 \%$ & & 0.254 & $x^{2}$ \\
\hline Read about it on the & nedia & 0 & & $0.0 \%$ & & 7 & & $2.3 \%$ & & 0.606 & $x^{2}$ \\
\hline Recommended by a & eighbor, friend, etc. & 4 & & $11,4 \%$ & & 16 & & $5,2 \%$ & & 0.758 & $x^{2}$ \\
\hline Family history of car & & 3 & & $8.6 \%$ & & 23 & & $7.5 \%$ & & 0.815 & $x^{2}$ \\
\hline For early cancer det & tion if present & 3 & & $8,6 \%$ & & 28 & & $9,2 \%$ & & 0.256 & $x^{2}$ \\
\hline Breast mass & & 3 & & $8,6 \%$ & & 11 & & $3,6 \%$ & & 0.682 & $x^{2}$ \\
\hline If no previous mam & graphy, why? & & & & & & & & & & \\
\hline Fear of radiation exp & sure during the procedure & 6 & & $10.3 \%$ & & 1 & & $1.0 \%$ & & 0.006 & $x^{2}$ \\
\hline Fear of a cancer diac & osis & 4 & & $6.9 \%$ & & 1 & & $1.0 \%$ & & 0.060 & $x^{2}$ \\
\hline Fear of pain during & e procedure & 3 & & $5.2 \%$ & & 10 & & $9,9 \%$ & & 0.720 & $x^{2}$ \\
\hline Considered not nec & sary & 26 & & $44.8 \%$ & & 59 & & $58,4 \%$ & & 0.654 & $x^{2}$ \\
\hline Financial hardship & & 0 & & $0.0 \%$ & & 5 & & $5.0 \%$ & & 0.159 & $x^{2}$ \\
\hline No knowledge of $\mathrm{m}$ & nmography & 19 & & $32,8 \%$ & & 25 & & $24,8 \%$ & & 0.105 & $x^{2}$ \\
\hline Age at first mammo & aphy & 49.0 & \pm & 6.2 & 49.0 & 46.0 & \pm & 6.7 & 45.0 & 0.004 & $x^{2}$ \\
\hline & $\leq 45$ years & 12 & & $34.3 \%$ & & 160 & & $52.3 \%$ & & & \\
\hline & $>45$ years & 23 & & $65.7 \%$ & & 146 & & $47.7 \%$ & & 0.044 & $x^{2}$ \\
\hline Difficulties during & No & 15 & & $42.9 \%$ & & 130 & & $42.5 \%$ & & & $x^{2}$ \\
\hline the procedure & Yes & 20 & & $57.1 \%$ & & 176 & & $57.5 \%$ & & 0.966 & $x^{2}$ \\
\hline If yes, why? & & & & & & & & & & & \\
\hline Pain & & 18 & & $51.4 \%$ & & 169 & & $55.2 \%$ & & 0.669 & $x^{2}$ \\
\hline Being half-naked & & 2 & & $5.7 \%$ & & 4 & & $1.3 \%$ & & 0.118 & $x^{2}$ \\
\hline $\begin{array}{l}\text { Fear of a cancer } \\
\text { diagnosis }\end{array}$ & & 0 & & $0.0 \%$ & & 2 & & $0.7 \%$ & & 1.000 & $x^{2}$ \\
\hline Difficult procedure & & 0 & & $0.0 \%$ & & 1 & & $0.3 \%$ & & 1.000 & $x^{2}$ \\
\hline Technician's lack of & idance & 0 & & $0.0 \%$ & & 1 & & $0.3 \%$ & & 1.000 & $x^{2}$ \\
\hline${ }^{t} \mathrm{t}$ test/ $\mathrm{x}^{2}$ chi-square & & & & & & & & & & & \\
\hline
\end{tabular}


Table 4 Difficulties during mammography

\begin{tabular}{|c|c|c|c|c|c|c|c|c|c|c|c|}
\hline & & & & difficulty & & & iffic & Ities pres & & & \\
\hline & & Mean & $=S D$ & $n, \%$ & Median & Mear & $\pm S[$ & $n, \%$ & Median & $P$ & \\
\hline Age at first mammo & aphy (year) & 47.7 & \pm & 6.7 & 47.0 & 45.3 & \pm & 6.5 & 45.0 & 0.001 & t \\
\hline Age at first & $\leq 45$ years & 59 & & $40.7 \%$ & & 113 & & $57.7 \%$ & & & 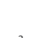 \\
\hline mammography & $\triangle 45$ years & 86 & & $59.3 \%$ & & 83 & & $42.3 \%$ & & & \\
\hline & Housewife & 111 & & $76.6 \%$ & & 141 & & $71.9 \%$ & & & \\
\hline Employment status & Retired & 11 & & $7.6 \%$ & & 16 & & $8.2 \%$ & & 0.600 & $x^{2}$ \\
\hline & Employed & 23 & & $15.9 \%$ & & 39 & & $19.9 \%$ & & & \\
\hline & Illiterate & 14 & & $9.7 \%$ & & 11 & & $5.6 \%$ & & & \\
\hline & Primary school & 71 & & $49.0 \%$ & & 96 & & $49.0 \%$ & & & \\
\hline Education status & Middle school & 15 & & $10.3 \%$ & & 17 & & $8.7 \%$ & & 0.510 & $x^{2}$ \\
\hline & High school & 24 & & $16.6 \%$ & & 34 & & $17.3 \%$ & & & \\
\hline & University & 21 & & $14.5 \%$ & & 38 & & $19.4 \%$ & & & \\
\hline${ }^{t} t$ test $/{ }^{x^{2}}$ chi-square & & & & & & & & & & & \\
\hline
\end{tabular}

Therefore, USG is not preferred in routine screening because it has low specificity and is not cost-effective when added to the screening program. USG is used as a guiding method in breast radiology, solid cyst differentiation, lesion characterization, investigation of the presence of other lesions, and biopsy. MRI is an expensive method, cannot be performed widely, and needs a specialist for evaluation.

It is used as an additional screening method to MMG and USG in women with high risk.(2) As an effective, easily accessible, reproducible, and inexpensive examination method, mammography is the most important test in breast cancer screening and has been performed for many years. Mammography refers to obtaining the film images using $x$-rays of the breast. The breasts are compressed with special plates and fixed to be imaged.

During scanning, craniocaudal and mediolateral oblique images of the breasts are taken. Conventional mammography involves the application of a radiation dose of 0.1 cGy per film. However, the currently used digital mammography method provides clearer images at a lower radiation dose. It allows for the diagnosis to be made when the disease is in very early stages. The risk of breast cancer does not increase with the dose of radiation applied during mammography.
Although mammography is a screening method with high sensitivity, it cannot detect all cancers. However, this does not decrease the importance of the procedure. The sensitivity of mammography is very high in fatty breasts. As the breast density increases, the sensitivity of mammography decreases; even if mammography is negative, additional imaging methods should be used in these patients. The experience and knowledge of the technical personnel that perform the mammography examination and the interpreting physician are of great importance in the success of the method $(3,4)$.

Mammography can be performed as a diagnostic or screening method. Screening mammography is applied in asymptomatic women to detect clinically occult breast cancer.

Screening can reveal asymptomatic diseases in a community based on tests and examinations that can be applied quickly. For screening to be performed, the disease should constitute an important health problem in the society, early diagnosis should be possible through screening, and it should provide an advantage in terms of treatment and reduced mortality. The screening method to be applied should be effective, acceptable for patients, easy to apply, cost-effective, and highly beneficial (5). Screening mammography 
is the most commonly used and most experienced screening tool in the world (6). In all age ranges, the sensitivity of screening mammography is $77 \%-95 \%$ and its specificity is $94 \%-97 \%$ (7). With screening mammography, 2-8 cancers are detected in every 1000 mammograms (8).

Studies on mammography continue in many countries globally. Eight prospective randomized trials of screening mammography have been conducted with approximately 500,000 female participants. In these studies, screening mammography was reported to reduce the risk of death by $15 \%$ in women aged $39-49$ years, by $14 \%$ in six studies that included women aged $50-59$ years, and by $32 \%$ in two studies evaluating women aged 60-69 years. Only one study included women aged more than 70 years, and the results were insufficient to recommend routine screening for this age group (9). Being cost-effective, easily accessible, reproducible, and highly specific for breast cancer makes mammography a suitable screening test. It remains the most important and effective examination in the diagnosis of breast cancer. However, the requirement of radiation, false-negative or falsepositive results leading to overtreatment, and pain experienced during scanning cause individuals to have concerns about undergoing this procedure. Despite this, many countries across the world implement mammography screening programs.

Different institutions and organizations have made different recommendations on the frequency of mammography and the age at which the first procedure should be performed. The American Radiology Association and the American Breast Imaging Association recommend annual mammography control from the age of 40 years. Similarly, the American Society of Obstetrics and Gynecology and the American Society of Breast Surgeons propose annual screening starting at the age of 40 years, as well as annual clinical breast examinations, which is consistent with the recommendations of radiologists. Since 2016, the United States Preventive Services Task Force (USPSTF) recommends screening every 2 years between the ages of 50-74 years while it indicates routine screening for the 40- to 49-year group. The American Academy of Family Physicians has also adopted the USPSTF recom- mendations. The American Cancer Society suggests that screening should be undertaken annually for the age group of 45-54 years and annually or biennially for those aged 54 and above, and continued until the individual has a life expectancy of 10 years. The same organization states that women can start having regular mammograms from the age of 40-44 years but emphasizes that this is a personal decision. The Canadian Task Force on Preventive Health Care, Finland, Denmark, the Netherlands, the United Kingdom, Switzerland, Switzerland, Norway, Germany, Belgium, and Luxembourg recommend screening every 2-3 years for those aged between 50 and 74 years. In Sweden, the age of starting screening is 40,45 , or 50 years, varying between different states. In Russia and Japan, screening is performed every 2 years from the age of 40 years. Also, no consensus exists around the world with regard to the age at which regular screening is no longer needed; some countries recommend this procedure until the age of 69 or 74 years, while others advocate for the continuation of screening as long as the individual is still healthy (6). In Turkey, the general recommendation for women aged $40-69$ years is mammography every 2 years. This recommendation was made taking into account the results of clinical and prospective studies, indicating the young population structure in Turkey and approximately half of the patients diagnosed with breast cancer being less than 50 years or premenopausal (10).

To further reduce the deaths due to breast cancer worldwide, the importance of screening should be emphasized, and women should be encouraged to undergo this procedure at recommended intervals. For a community screening to be considered successful, $70 \%$ of the target audience must participate in screening. There have been efforts all over the world, including Turkey, to increase the rates of mammography. For this purpose, it is very important to identify the aspects of mammography about which society is misinformed. Increasing public knowledge about mammography by emphasizing these aspects may increase the rate of mammography, allowing more patients with breast cancer to be diagnosed in earlier stages. Early diagnosis and treatment may increase patients' surveillance and reduce treatment costs. The 
present study aimed to reveal the views of the target population on mammography. The most effective factor in women having mammographic screening was the guidance of the clinician. Clinicians should direct women to mammographic screening regardless of the branch to increase the rate of mammography. Also, the emphasis on mammographic screening by the media may increase the mammography rates with the cooperation of health institutions and the government. In the present study, the most reported (53.5\%) among the reasons for not undergoing mammography, was personally considering it to be an unnecessary procedure. It is important to improve the knowledge level of the society about breast cancer and mammography so as to change this view and increase the number of screenings. All health institutions, healthcare personnel, nongovernmental organizations, municipalities, provincial and district administrations, and press and media organizations should act together to increase the knowledge and awareness of the society on breast cancer and screening. For many years, it has been acknowledged that increasing the education level of society has a positive effect on public health, which is supported by the findings of the present study in this particular context.

Women may have anxiety related to mammography, and this is caused by radiation exposure and pain experienced during the procedure. The public should be informed that only low-dose radiation is applied, and the side effects are insignificant. Many studies reported that women experienced pain during mammography. In the present study, 187 participants with a history of mammography complained about pain during the procedure. Since it is necessary to compress the breast to obtain a quality image, this can be painful for some individuals (11). Pain experienced can cause the person to stop attending regular screening procedures, or in a worse case, the fear of pain may result in the person not considering the procedure at all. Therefore, it is important to reduce pain that may occur during the procedure. For this purpose, it is recommended that mammographic examinations are performed with appropriate devices by previously trained technical personnel. Before scanning, informing the individual that pain may occur, providing ap- propriate definitions, and giving painkillers before the procedure may make the person feel less pain. In a previous study, it was stated that the careless treatment of women during mammography triggered the development of pain and anxiety (12). One of the aims of the present study was to raise awareness of breast cancer and mammography in the women who participated in the study. Of the 500 women participating in the survey, 159 reported that they had not undergone mammography for various reasons, and 101 of these women $(63.5 \%)$ stated that they would be willing to undergo mammography in the future.

\section{CONCLUSIONS}

The most effective way to reduce mortality and morbidity in breast cancer is early diagnosis and treatment, and the most effective method of early diagnosis is screening mammography in the community. Increasing the awareness of the society on breast cancer and mammography may facilitate the detection and treatment of breast cancer. Mammography is the most effective imaging method in detecting breast cancer. Understanding the view of women between the ages of 40-69 years on mammography and developing appropriate policies in this direction may reduce losses due to breast cancer.

\section{REFERENCES}

1. https://gco.iarc.fr/today/data/factsheets/cancers/20-Breastfact-sheet.pdf

2. Meme Kanseri Tarama Rehberi; Türk Radyoloji Derneği, TRD Yeterlilik Kurulu, Rehberler ve Standartlar Komitesi,2011. Date of access:12/29/2020.

3. Brunicardi FC, Andersen DK, Billiar TR, Dunn DL, Hunter JG, Matthews JB, Pollock RE, Schwartz Cerrahinin İlkeleri, p 523$527,2016$.

4. Özmen V, Cantürk Z, Çelik V, Güler N, Kapkaç M, Koyuncu A, Müslümanoğlu M, Utkan Z, Meme Hastalıkları Dernekleri Federasyonu, Meme Hastalıkları Kitabı, p 109, 2012.

5. Loberg M, Lousdal ML, Bretthauer M, Kalager M. Benefits and harms of mammography screening. Breast Cancer Res. 2015; 17: 63 .

6. Gültekin S et all. Turkiye Klinikleri J Med Oncol-SpecialTopics 2018;11:13- 22.

7. Breast Cancer Surveillance Consortium(BCSC). Sensitivity and specificity of for 2.264 .089 screening mammography examinations from 2002-2006. August 9, 2012.

8. Miglioretti DL, Ichikawa L, Smith RA, et al. Criteria for identifying radiologists with acceptable screening mammography interpretive performance on basis of multiple performance measures. AJR Am J Roentgenol 2015;204:486-91. 
9. Nelson HD, Tyne K, Naik A et al. Screening for breast cancer:An update for the U.S. Preventive Services Task Force. Ann Intern Med 2009;151:727-737.

10. T.C Sağlık Bakanlığı Meme kaseri korunma, tarama, tanı, tedavi ve izlem klinik rehberi, 2020.

11. Mainiero Mb, Schepps B,Clements NC, Bird CE, Mammography- related anxiety effect of preprocedural patient education. Women's Health Issues. 20001; 11: 110-5.

12. Coşar S, Coşar B, Candansayar S, Özdemir A. Mastalji yakınması ile radyolojik incelemeye alınan hastalarda hostilite, aleksitimi ve depresyon düzeyleri. Yeni Symposium. 2001;39: 181-184. 